\title{
The Estimation of Winter Wheat Yield Based on MODIS Remote Sensing Data
}

\author{
Linsheng Huang ${ }^{1,2}$, Qinying Yang ${ }^{1,2}$, Dong Liang ${ }^{1}$, Yansheng Dong ${ }^{2}$, \\ Xingang $\mathrm{Xu}^{2}$, and Wenjiang Huang ${ }^{2, *}$ \\ ${ }^{1}$ Key Laboratory of Intelligent Computing \& Signal Processing, \\ Ministry of Education, Anhui University, Hefei, 230039, P.R. China \\ ${ }^{2}$ Beijing Research Center for Information Technology in Agriculture, \\ Beijing, 100097, P.R. China \\ linsheng0808@163.com, huangwj@nercita.org.cn
}

\begin{abstract}
A yield estimation method by remote sensing was used to estimate the yield of winter wheat in Jiangsu province, China. The first step of this study was to extract the planting area of winter wheat from environmental satellite images and land -use map of Jiangsu province, meanwhile, correlation analyses were performed by using 8-day of composite Leaf Area Index (LAI) data from Moderate Resolution Imaging Spectroradiometer (MODIS) and statistical yield of corresponding counties. Secondly, the average LAI was calculated at the optimal growth period, and the statistical yields of wheat for all counties were collected, in which the former was chosen as the independent variable and the latter was the dependent variable, and the regression model was established. Finally, the accuracy and stability of the regression model were validated using the data of another year. The results indicated that the yield estimation model at provincial level was reliable, the Root Mean Square Error (RMSE) and the Mean Absolute Error (MAE) of the model was $12.1 \%$ and $9.7 \%$, respectively. In addition, the yield estimation system of winter wheat in Jiangsu province was constructed and published based on ArcMap and ArcGIS Server.
\end{abstract}

Keywords: LAI, remote sensing, yield estimation, regression model, ArcGIS Server.

\section{O Introduction}

With the increase of population and the reduction of arable land, food security has become a very serious and prominent issue around the world, especially in China. Winter wheat is one of the major crops in China, its planting area accounts for one-fifth of the total crops area nationwide. Timely and accurate estimation of the winter wheat yield has an important significance for a country to enhance the risk management of food security as well as to develop appropriate market policies[1-3].

${ }^{*}$ Corresponding author. 
Currently, a range of methods have been used for estimating crop yield[4-8]. These methods, however, have their own drawbacks respectively. The statistical surveys methods are time-consuming and require a lot of manpower and material resources; agricultural weather forecasting methods and agricultural forecasting methods are not suitable for large-scale crop yield estimation.

As satellite technologies improved significantly in recent years, remote sensing has become an important method to monitor and gather agricultural information in practice. Compared with these methods mentioned above, remote sensing yield estimation methods, by means of particular advantages such as large coverage, short monitoring cycle, strong instantaneity as well as low cost, have provided new technological means for the realization of large-scale crop yield estimation. Remote sensing yield estimation methods include crop growth model method, semi-empirical and semi-mechanistic model method and empirical model method. They have their own advantages and disadvantages, crop growth model method requires a lot of input parameters (such as meteorological parameters, management parameters and crop genetic parameters, etc.), which limits the use in large regions because some of the parameters are not easy to obtain in these areas. Also, it is difficult to simulate some parameters in semi-empirical and semi-mechanistic model method. Empirical model method though has some limitations, is a simple and suitable method for large-scale crop yield estimation under certain accuracy conditions. By using this method, many scholars at home and abroad had made outstanding achievements in crop yield estimation[9-10]. Ren et al. (2010) estimated regional winter wheat yield based on the inversion of LAI, the yield of winter wheat could be accurately forecasted 20-30 days prior to harvest, the results indicated that LAI and crop yield have a good correlation[9]. Becker-Reshef et al. (2010) utilized the maximum of Normalized Difference Vegetation Index (NDVI) in crop growing season to estimate yield, the error was less than 10\%[10]. Mkhabela et al. (2011) developed a productionNDVI model to estimate crop yield, in which the NDVI values were selected at the optimal estimation period (the period when correlation coefficient of NDVI values and the yields is largest) [11]. Based on previous studies, this study estimated the winter wheat yield with LAI at the optimal estimation period in Jiangsu province.

\section{Study Area and Data Processing}

\subsection{Study Areas}

Jiangsu province is located in eastern coast of China mainland which is the transition zone of subtropical to tropical region, between longitude $116^{\circ} 18^{\prime}-121^{\circ} 57^{\prime}$ and north latitude $30^{\circ} 45^{\prime}-35^{\circ} 20^{\prime}$, the geographic range shown in Figure 1(a). Its average temperature is $13^{\circ} \mathrm{C}-16^{\circ} \mathrm{C}$ and annual rainfall is about $1000 \mathrm{ml}$, the area of arable land is 4,902 million hectares, accounting for $3.97 \%$ of nationwide. It is one of the most important food sources in China, growing areas of winter wheat shown in Figure 1(b). 

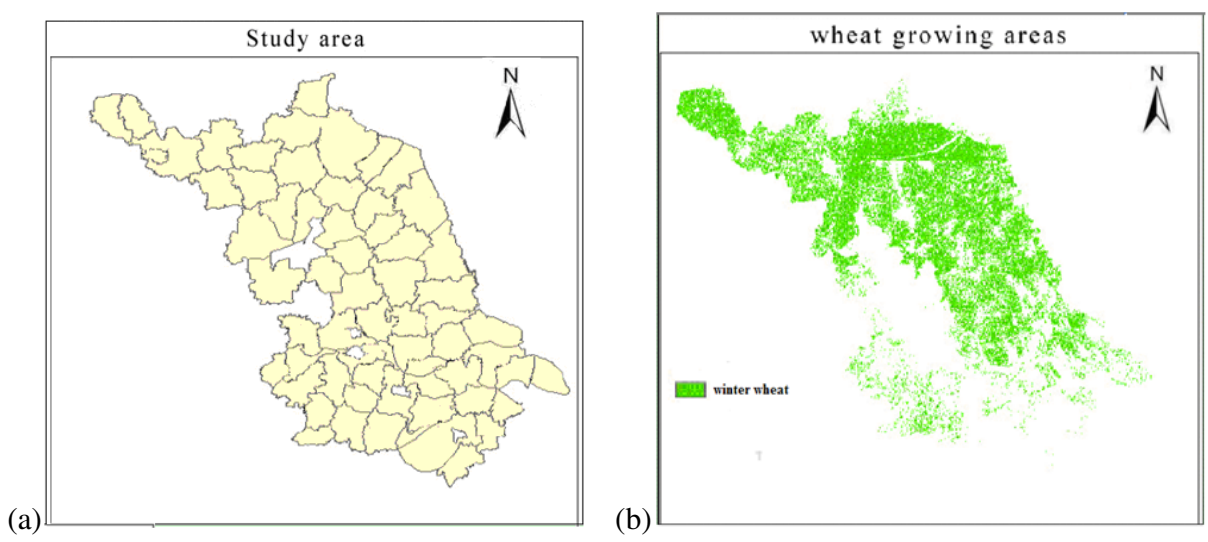

Fig. 1. The study area $(a)$ and growing areas of winter wheat $(b)$ selected in this study

Winter wheat in Jiangsu Province was sowed at the period of early to mid October, matured at about late May to early June, the phenophase of winter wheat is shown in Table 1.

Table 1. Phenophase of winter wheat in Jiangsu province

\begin{tabular}{|c|c|c|c|c|c|c|c|c|c|}
\hline \multirow{2}{*}{$\begin{array}{c}\text { Month } \\
\text { Date }\end{array}$} & \multirow[b]{2}{*}{ early } & \multirow{2}{*}{$\frac{\text { Feb }}{\text { mid-late }}$} & \multicolumn{2}{|c|}{ Mar } & \multicolumn{2}{|r|}{ Apr } & \multicolumn{2}{|c|}{ May } & \multirow{2}{*}{$\frac{\text { Jun }}{\text { early }}$} \\
\hline & & & $\begin{array}{l}\text { early } \\
\text {-mid }\end{array}$ & late & early & $\begin{array}{l}\text { mid- } \\
\text { late }\end{array}$ & $\begin{array}{l}\text { early- } \\
\text { mid }\end{array}$ & late & \\
\hline Stage & $\begin{array}{l}\text { winter } \\
\text { ing }\end{array}$ & $\begin{array}{l}\text { turning } \\
\text { green }\end{array}$ & $\begin{array}{l}\text { erect } \\
\text { ing }\end{array}$ & $\begin{array}{l}\text { join } \\
\text { ting }\end{array}$ & $\begin{array}{l}\text { bootin } \\
\mathrm{g}\end{array}$ & $\begin{array}{l}\text { headi } \\
\text { ng }\end{array}$ & $\begin{array}{l}\text { flowe } \\
\text { ring }\end{array}$ & matu & ity \\
\hline
\end{tabular}

\subsection{Data Processing}

This study utilized the data of environmental satellite and the land use map of 2009 to extract the information of winter wheat growing areas and got the average LAI of county scale from MODIS products. By using the remote sensing images of environmental satellite, the information of winter wheat growing areas was extracted in 16 April and 18 April, 2009. The process of preprocessing included radiometric calibration, atmospheric correction as well as geometric correction. The first step was using the land use map of Jiangsu province to mask remote sensing images which had been preprocessed by which environmental satellite images within the scope of cultivated land obtained, and then through the process of supervised classification for satellite images (which had been masked) to extract the winter wheat growing areas. The principle of winter wheat extraction is: there were almost no other crops grown in Jiangsu province in April, therefore the green vegetation in arable land can be regarded as winter wheat. The next step was stitching the winter wheat growing areas of the images, which captured in April 16 and April 18, 2009 to form an integrated image of Jiangsu Province. In order to match the pixels of MODIS-LAI data, this study resampled the spatial resolution of $30 \mathrm{~m}$ to that of $1 \mathrm{~km}$ in these areas. Also, it 
assumed that the wheat growing areas varied slightly at the county scale on the condition that the spatial resolution was $1 \mathrm{~km}$. Meanwhile, the wheat growing areas of 2009 could be used as that of 2006 and 2007, as shown in Figure 1(b). LAI data used in this study came from MOD15A2 which is a product of MODIS. The advantages of MODIS data as below: short repetition period, large coverage area and strong access ability. After the process of smoothing and denoising, MOD15A2 data was reprojected with MODIS Reprojection Tool (MRT), and the projection types were geographic latitude-longitude projection and WGS84 coordinates system. In order to get data of wheat growing areas in Jiangsu province, h27v05 and h28v05 (track number) were stitched in ENVI software in this study. Next, the LAI data in wheat growing areas would be reached by utilizing the wheat areas to mask the stitched images. A total of 64 scenes of MOD15A2 data were adopted in this study, the time range covered the seven critical growth stages of winter wheat (turning green, erecting, jointing, booting, heading, flowering and milky mature) from 2006 to 2007 .

\section{Estimation Methods and Results Analysis}

\subsection{Estimation Methods}

As different crops have different spectral information, firstly satellite sensors are used to record information of the surface and identify the type of crops, then extract various vegetation indices to establish the relationship between vegetation index and crop yield, and finally use vegetation indices for estimation, this method is called yield estimation [12]. LAI is defined as the ratio the projected area of the leaves to that of the total area when the sunlight is direct. Crop LAI is an important parameter in the process of material exchange with the environment, and it directly relate to photosynthesis, respiration, transpiration and biomass accumulation of crop and has significant impact on the yield of crop [13-14]. LAI used in this study was the average number in the county scale, which was got through the statistical computation of MOD15A2 product in wheat growing areas. Also, the LAI of winter wheat growing areas in each county and the number of pixels corresponding to these areas were counted in ArcMap. Total number of LAI in winter wheat growing areas divided by the number of pixels will get the average LAI of the winter wheat in this county. Due to the correlation between LAI at different periods and crop production is different, firstly through the correlation analysis of average LAI at county-scale and statistical yield in a county in 2006, then selected the period which correlation coefficient was largest as the optimal estimation period. Furthermore, this study utilized the average LAI of this period and statistical yield for linear regression to obtain a provincial-scale estimation model. Estimated yield of 2007 would be obtained when substituted the average LAI of each county at the optimal estimation period in this year into estimation model. Finally, accuracy of the model would be got through the comparison and validation of estimated yield with statistical yield.

RMSE and MAE are the two indicators for validate the accuracy of yield estimation model. RMSE and MAE are defined as follow: 


$$
\begin{gathered}
R M S E=\sqrt{\frac{1}{n} \sum_{i=1}^{n}\left(P_{i}-M_{i}\right)^{2}} \\
M A E=\frac{1}{n} \sum_{i=1}^{n}\left|P_{i}-M_{i}\right|
\end{gathered}
$$

where $n$ is the number of counties for estimation in Jiangsu Province, $P i$ is the estimated yield and $M i$ is the statistical data. The percentage values of RMSE and MAE can be obtained when the values of them divided by the average value of statistical yield. RMSE can well reflect the accuracy of predicted values, when RMSE is less than $10 \%$ indicates that the consistency of predicted and actual values is very good, when the number is less than $10 \%$ and greater than $20 \%$ shows the predicted results are good, between $20 \%$ and $30 \%$ means predicted results are general, greater than $30 \%$ indicates large deviations[11].

\subsection{Result Analysis}

At the period from turning green to maturity stage of winter wheat in 2006, through the correlation analysis on the average LAI every 8 days and the statistical yields in each county, the results shown in Figure 2(a). The correlation coefficient of winter wheat LAI and yield was maximum in the first 97 to 121 days of the year, up to 0.6. It also showed that the booting to heading stage was the optimal yield estimation period for winter wheat in Jiangsu province because this period was very important in the process of reproductive growth and yield formation.

(a)

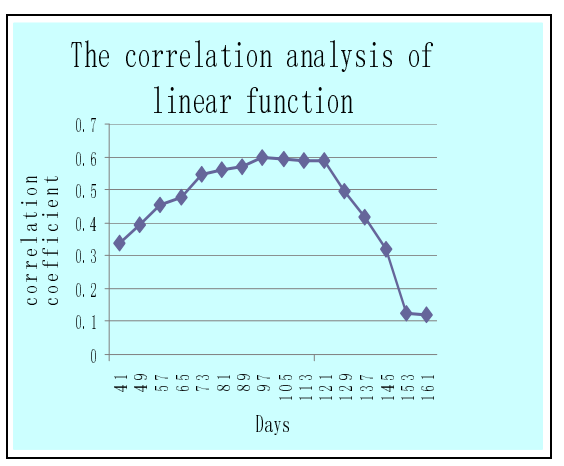

(b)

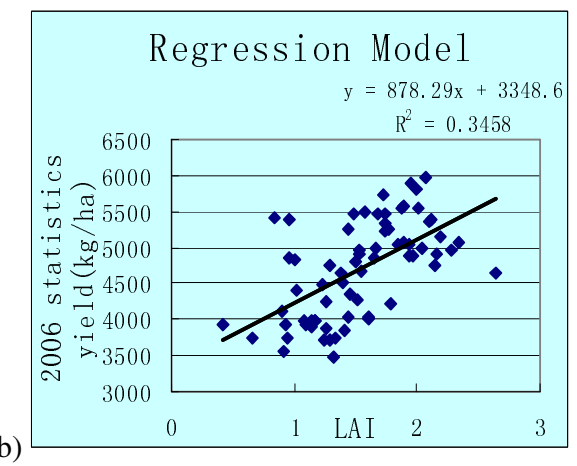

Fig. 2. The correlation analysis $(a)$ and relationship between wheat yield and LAI $(b)$

In this study, through the linear regression of the LAI at heading stage and statistical yield of winter wheat in each county in 2006, the yield estimation model will be reached, as shown in Figure 2(b). The regression equation is:

$$
y=878.29 x+3348.6
$$


where $y$ is the yield of winter wheat, $x$ is the average LAI at heading stage. As can be illustrated from Figure 2(b) that LAI and yield are correlated remarkably.

When substituted the average LAI at heading stage in 2007 into regression model, the yield estimation of each county and the spatial distribution of winter wheat yield in 2007 will be reached, as shown in Figure 3(a). In order to validate the results, this study compared the estimated yield with statistical yield in Figure 3(b). RMSE and MAE of wheat yield estimation was $12.1 \%$ and $9.7 \%$ respectively, it showed that the accuracy of yield estimation model was satisfactory.

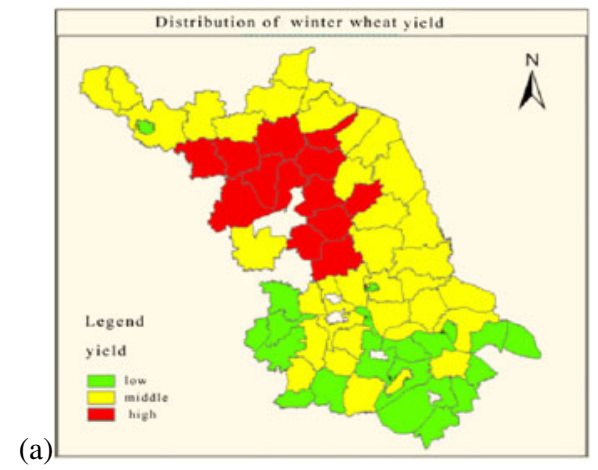

(b)

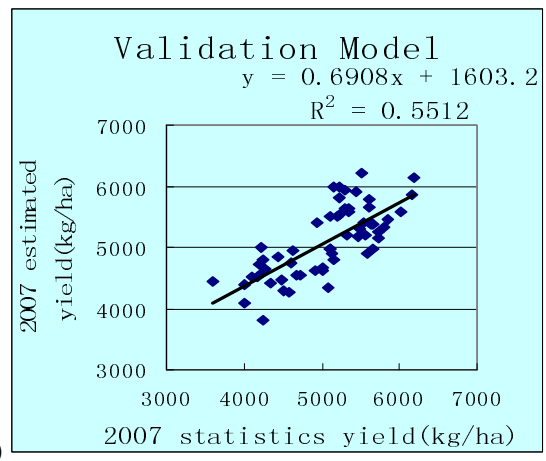

Fig. 3. Distribution of winter wheat yield $(a)$ and accuracy validation of yield estimation model in $2007(b)$

\section{Implementation of Web Publishing System}

Web services make it possible for service providers to sell their services by publishing their availability over the Internet. They provide a standard means of interoperating between different software applications, running on a variety of platforms or frameworks. ArcGIS Server is developed by ESRI based on ArcObjects (AO) components; the aim of it is to build enterprise-class Geographic Information system (GIS). AO components provide a wealth of features, including access to GIS data, maps performance and spatial analysis, etc[15]. Map Service function of ArcGIS Servers are mainly used in this study. Before calling the estimation data, the data must first be published as the configuration information of map layer. The map layer is designed in ArcMap, the basic functions of it including zoom, layer stack as well as inserting data to the layer, the output map is saved as mxd format. A service object will be created in the interface of ArcGIS Server Manage by double-clicking the Add New Service, entering the name of the service object and the folder where the published map located, and the published map is a active layer[16].

This study uses the JavaScript language and calls the components of ArcGIS through API to build the published system. The system is developed in the .net framework of Microsoft Visual Studio 2008, where js file (a script file of JavaScript) can be directly executed. The function modules of the system including basic map functions, layer management as well as search functions. The function menus and the operation interface of the system showed in Table 2 and Figure 4, respectively. 
Table 2. function menus of the system

\begin{tabular}{|c|c|c|}
\hline Function modules & Specific functions & Function description \\
\hline basic map functions & zoom, roam, view & $\begin{array}{l}\text { facilitate the access of } \\
\text { map }\end{array}$ \\
\hline layer management & add \&delete layer & $\begin{array}{l}\text { highlight layer } \\
\text { information }\end{array}$ \\
\hline search functions & search for yield data & in favor of data sharing \\
\hline
\end{tabular}

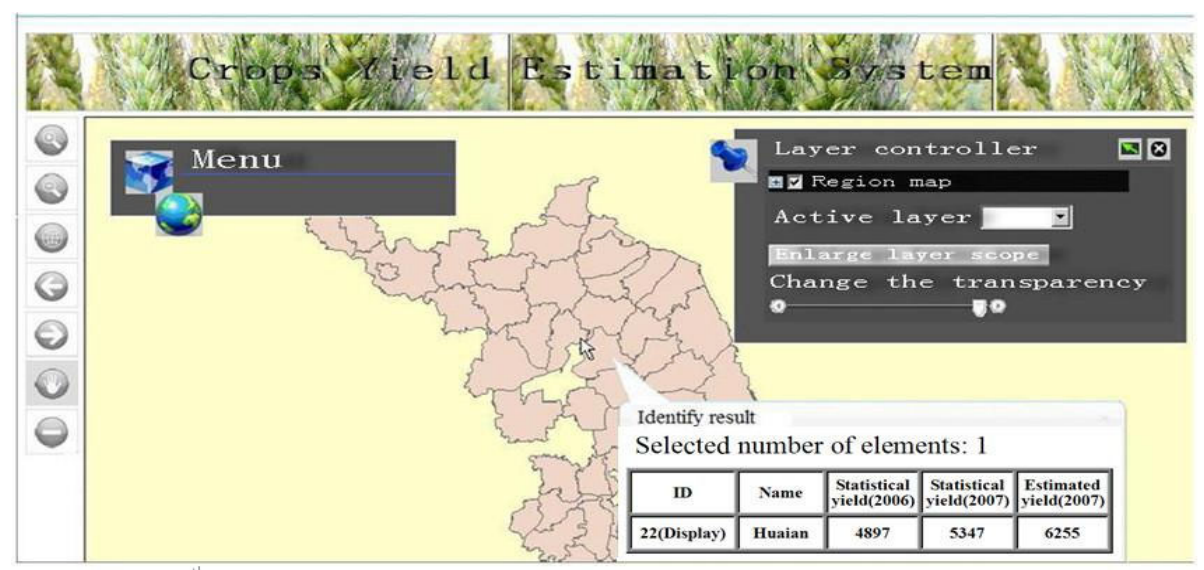

Fig. 4. Operation interface of yield estimation system

\section{Discussion and Conclusions}

Based on the data of MODIS products, this study established the model of winter wheat yield estimation by selecting the average LAI at the optimal estimation period and statistical yield data (2006-2007) of each county in Jiangsu province. The accuracy of the model was quite satisfactory through the validation of detailed data. Winter wheat yield can be estimated one to two months prior to harvest, which provide the scientific basis for the local government to make appropriate food policies. In addition, for the purpose of information sharing, this study designed a Web publishing system to publish the data of wheat yield.

Despite these good results, there are still some inadequacies in this study:

1 , the current model was developed based on the 2 years of data available and the accuracy of the model was validated only by 1 year of data, the results were lack of universality because of the small amount of data;

2 , the constructed environment of the model was relatively simple in which the impact of natural disasters and other factors on yield were not carefully considered;

3 , the functions of the Web publishing system were not perfect and needed to further improvement.

Consequently, further studies are needed to resolve these drawbacks mentioned above. 
Acknowledgements. This study was subsidized by the National Natural Science Foundation of China (41001244,41071276) and Key Research Project of Education Department of Anhui Province(KJ2010A020, KJ2010A021).

\section{References}

1. Li, M.Z., Li, P., Wang, Q., Fang, J.Q., Wang, M.H.: Development of an Intelligent Yield Monitor for Grain Combine Harvester. In: Artificial Intelligence Applications and Innovations. IFIP, pp. 663-670 (2005)

2. Huang, W.J., Wang, J.H., Wang, Z.J., Zhao, C.J., Liu, L.Y., Wang, J.D.: Inversion of Foliar Biochemical Parameters at Various Physiological Stages and Grain Quality Indicators of Winter Wheat With Canopy Reflectance. Int. J. Remote Sens. 25, 2409-2419 (2004)

3. Xu, X.G.: Research of Crop Yield Models. Chinese Academy of Sciences, Beijing (2007)

4. Liu, L.Y., Wang, J.H., Huang, W.J., Zhao, C.J., Zhang, B., Tong, Q.X.: Improving Winter Wheat Yield Prediction by Novel Spectral Index. Trans. Chin. Soc. Agric. Eng. 20, 172-175 (2004)

5. Li, R., Li, C.J., Xu, X.G., Wang, J.H., Yang, X.D., Huang, W.J., Pan, Y.C.: Active Solar Heating System With Soil Heat Storage for Plastic Film Greenhouse and Its Effects. Trans. Chin. Soc. Agric. Eng. 25, 114-117 (2009)

6. Li, W.G., Wang, J.H., Zhao, C.J., Liu, L.Y.: A Model of Estimating Winter Wheat Yield Based on TM Image and Yield Formation. J. Triticeae Crops. 27, 904-907 (2007)

7. Tang, Y.L., Wang, J.H., Huang, J.F., Wang, R.C.: Yield Estimation by Hyperserctral Data of Rice Canopies in Mature Stages. Acta Agron. Sin. 30, 780-785 (2004)

8. Wang, T., Zhang, L.D., Lao, C.L., Zhao, L.L., Li, J.H., Wang, Z.Y., Huang, W.J., Wang, J.H., Yan, Y.L.: Study on NPLS Model with Three-Dimensional Hyperspectrum for Assessing Per-Mu-Yield of Winter Wheat. Spectrosc. Spectral Anal. 26, 1915-1917 (2006)

9. Ren, J.Q., Chen, Z.X., Zhou, Q.B., Tang, H.J.: LAI-based Regional Winter Wheat Yield Estimation by Remote Sensing. Chin. J. Appl. Ecol. 21, 2883-2888 (2010)

10. Becker-Reshef, I., Vermote, E., Lindeman, M., Justice, C.: A Generalized RegressionBased Model for Forecasting Winter Wheat Yields in Kansas and Ukraine Using Modis Data. Remote Sens. Environ. 114, 1312-1323 (2010)

11. MKhabela, M.S., Bullock, P., Raj, S., Wang, S., Yang, Y.: Crop Yield Forecasting on the Canadian Prairies Using MODIS NDVI Data. Agr. Forest Meteorol. 151, 385-393 (2011)

12. Deng, R., Huang, J.F., Wang, F.M., Sun, H.S., Peng, D.L.: Research on Yield Estimation of Rice Based on Remote Sensing Using Moderate-Resolution Imaging Spectroradiometer(MODIS) Data:A Case Study of Jiangsu Province, China. Chin. J. Rice Sci. 24, 87-92 (2010)

13. Chen, J.S., Huang, J.X., Lin, H., Pei, Z.Y.: Rice Yield Estimation by Assimilation Remote Sensing Into Crop Growth Model. Sci. China Ser. F. 40(suppl.), 173-183 (2010)

14. Bai, L., Wang, J., Jiang, G.Y.: Study State and Developing Trends of Hyperspectral Remote Sensing Technology in Estimating Crop Yield. Mod. Agr. 1, 30-33 (2006)

15. Zhao, P., Liu, G., Zhang, X.J., Li, M.Z.: A Method to Develope WebGIS Based on ArcIMS and Application. App. Res. Comput. 22, 258-260 (2005)

16. Yang, F.P., Li, L., Feng, J.F., Wu, Z.T.: Research on integration method of GIS-based application model based on web service composition. Computer Engineering and Des. 1, 133-137 (2011) 